\title{
Protecting the sportsman's brain (concussion in sport) Annual Guest Lecture 1990, London Sports Medicine Institute
}

\author{
Allan J. Ryan MD
}

\section{Definition of the problem}

Success in many ventures is evaluated by the ability to realize stated objectives. This ability is favoured by clearly defined goals described accurately in precise terms. If the objective is to protect the brains of athletes the goals must be to determine the sports and particular events in which the brain is at risk, to obtain reports of the occurrence of injuries to athlete's brains and the related circumstances, to learn the specific signs and symptoms that will indicate that a brain injury has occurred, to decide on the management of the athlete who has sustained a brain injury and to identify means by which such injury can be prevented or at least ameliorated.

These goals have been established by sports medicine practitioners and have been addressed with varying degrees of success for sports in general and for some sports in detail. Implementation has been hampered by the use of imprecise terminology, lack of agreement on desirable management of the injured, failure to establish and enforce playing rules to enhance safety, difficulties in obtaining and applying advanced diagnostic technology, persistence in coaching dangerous techniques of play and of athletes using such techniques, problems in the development of and reliance upon protective headgear, economic pressures, and tradition regarding the image of the athlete.

Because the actions of the players in many sports must be very rapid in moving towards goals or terminations of their efforts, sometimes through the aggregation or opposition of other players or through or over a variable environment, it is necessary for them to be able to see clearly and respond quickly, often in unexpected and unpredictable ways. This means that the head must be directed forward and into the field of action, rendering it vulnerable to injury. Injuries to the head may occur in sports as diverse as gymnastics and showjumping but epidemiological research demonstrates that they are most common in sports where there is violent contact between competitors such as American football,

Address for correspondence: Allan J. Ryan, Sports Medicine Enterprise, 4570 West 77th Street, Minneapolis, MN 55436, USA (C) 1991 Butterworth-Heinemann Ltd. 0306-3674/91/020081-06
Rugby League, boxing, wrestling and ice hockey, or where the speed of the athlete impelled by motors or sleds may bring him into violent contact with his environment.

This brings us to two related problems: the identification of the fact that an injury has occurred and, if so, its particular nature. Frequent loose use of the term 'head injury' brings up the question whether the external or internal structures of the head, or both, have been injured. Inspection and palpation can identify the external injuries with helmet, face mask and mouthguard removed, but the internal injury may require observation of the player's behaviour, including speech and response, as well as consciousness and awareness of the environment, pupillary reaction and, even more importantly, the patience to continue the observation until significant signs and symptoms appear. Beyond the immediate period, the use of radiological or imaging techniques and the monitoring of vital signs over time may be necessary before a diagnosis can be made. Attention directed to an external injury may distract the attendants from an associated internal injury.

\section{Concussion}

Concussion can be defined as a sharp sudden blow or collision. The term has been used in a medical sense as designating an injury resulting from impact or violent agitation with or without some loss of function. In this sense it describes a syndrome, a sum of signs and symptoms associated with a pathological process. The term 'cerebral concussion' is less precise than cerebral commotion since the pathological process tends to defy specific description. In the face of this confusion, clinicians continue to distinguish three degrees of cerebral concussion and make recommendations for management based on this classification. The best that can be said for this classification is that after the victim has been carefully studied and observed over a period of at least $24 \mathrm{~h}$ from its onset, it may be useful in his subsequent management. We know from experience that the concussion syndrome occurs at times in players who do not openly manifest signs or symptoms, continue to perform and may not report it until a day or more later, at which time they may do so only because of headache. Certainly, to take action regarding the continuance of play within a few minutes of the 
occurrence of injury is premature and, in my estimation, inadvisable.

Cerebral concussion is a serious injury and currently there is no serious injury occurring in athletes that is managed in general as poorly. Neither physicians nor the the sports public, including the athletes, take it very seriously; chiefly, I believe, because its apparent effects seem to be transient, and because they have little understanding about what has happened in the brain to produce these effects, and what may still be happening when these effects are no longer observed externally and directly.

Cerebral concussion is often defined as a transient dysfunction of the brain which may result in loss of consciousness, dysequilibrium and temporary mental confusion. In fact, the examination of brains of animals that have been concussed shows evidence of cell damage in both the white matter and brain stem, and similar findings have been observed in the brains of humans who have died suddenly following multiple injuries including concussion. Hugenholtz and Richard ${ }^{1}$ have said: 'Concussions have always been regarded as minor injuries not causing visible brain damage, yet widespread microscopic changes have been documented. These include petechial hemorrhages in periventricular regions, axonal changes suggestive of shear injuries throughout the white matter of the hemispheres and brain stem, and chromatolysis and cell loss throughout the cortical grey matter and brain stem nuclei ${ }^{2-4}$. These abnormalities may evolve into gross atrophy after repeated injury.'

Gurdjian ${ }^{5}$ said, 'It is our impression that concussion is due to pressure gradients in the brain stem following a blunt head impact.' He could have added that it can be produced by sudden acceleration or decelerating of the brain even if there is no impact on the head. If the concussion is produced by a blow to the head, the effects in the brain may to some extent be dependent on the dampening effect of the scalp, the degree of the deformity of the cranium and the pressure changes in response to the contrecoup effect, according to Lindgren ${ }^{6}$.

That something of serious significance has happened to the concussed brain has been verified by several clinical studies relating to brain function in terms of memory and reasoning. Amnesia for the events immediately preceding the concussion is common and may be permanent. It was not present immediately after the event in six football players reported by Lynch and Yarnell ${ }^{7}$ but began at least $30 \mathrm{~s}$ later, indicating an ongoing difficulty in information processing. Ability to process information at a normal rate has been shown by Gronwall and Wrightson ${ }^{8}$ to be impaired in most subjects for periods of time varying up to 35 days. In others with such postconcussion symptoms as fatigue, irritability, persistent headache and poor concentration, slow processing continued after 35 days. When the same authors studied 20 young adults after a second brain concussion ${ }^{9}$ they found that their information processing capability was less than controls who had only one concussion, and they took longer to recover. External brain scanning of 70 patients with postconcussion symptoms showed that they had a $15 \%$ greater mean cerebral circulation time than 70 controls, according to Taylor and Bell ${ }^{10}$.

Rimel et al, ${ }^{11}$ followed 424 persons who had been discharged after admission to the outpatient emergency service at the University of Virginia Hospitals because of head injury. Most were discharged without admission to the inpatient service after a thorough examination including skull $\mathrm{X}$-ray films with a diagnosis of 'minor head injury'. The criteria for inclusion in the follow-up study were a history of unconsciousness not exceeding $20 \mathrm{~min}$, a Glasgow Coma Scale rating of 13 to 15 , and hospitalization not exceeding $48 \mathrm{~h}$. Follow-up after 3 months included a history of events since the accident, assessment of subjective complaints, a neurological examination, a psychological assessment for life stress, a neuropsychological test to measure higher cortical function, and an evaluation of employment status. Of those who had been gainfully employed before the accident, $34 \%$ were unemployed, $79 \%$ complained of persistent headaches and 59\% described problems with memory. Although the neurological examination was completely normal in nearly all, neuropsychological testing showed problems with attention, concentration, memory or judgment in most of the 69 patients evaluated. Emotional stress caused by persistent symptoms seemed to be a factor in long-term disability. Mean age of the patients was 27 years and most were between 11 and 20 years of age. Sixty-six per cent were male. Less than half the injuries were due to road traffic accidents. Only $5 \%$ had a skull fracture.

That head and brain injuries are not uncommon in sports is borne out by the fact, in Scotland in 1974, of 84000 patients with such an injury attending accident and emergency departments $9240(11 \%)$ were due to sports, according to the Scottish Head Injury Management Study ${ }^{12}$. Of the sports injuries, only one-quarter were admitted to the inpatient service and so the remainder were presumably considered to be 'minor'. Of 424 patients with head injuries admitted to the neurosurgical unit at Southern General Hospital in the same year, $7 \%$ were due to sport. The sports most frequently responsible were golf, horse-riding, soccer, shooting, climbing and rugby. Only four were due to boxing. There was only one death, in a climber, but $12 \%$ were subsequently moderately to severely disabled, and post-traumatic epilepsy developed in 12 patients $(23 \%)$, ten within 7 days of injury.

In the typical sports situation, whether it is a practice session or a competition, if there is no physician present the player who receives a concussion but does not lose consciousness is not usually identified as having such an injury, and if he feels able to do so he continues playing. He may remark that he was 'dinged' or saw stars, and may complain of a headache. Team-mates, opponents or a coach or official may note some confusion in his behaviour, but it is usually taken very lightly. Afterwards, whether he sees a physician or not depends usually on whether or not he has a severe headache. If he has a short period of unconsciousness he may be asked to sit or lie down for a few minutes. If he can answer questions correctly and does not show gross dysequilibrium, he soon returns to practice or play.

If a physician is present he may notice that a player 
who has not been unconscious is manifesting unusual behaviour and get him out for an examination. If the player can answer simple questions correctly and shows no abnormal neurological signs he will usually be sent back into play. If he complains of headache he may be given an aspirin. A player who has been briefly unconscious is usually held out of play for a few minutes, but if he can tell what day it is and the name of the opponents and shows no abnormal neurological signs he also goes back into play.

Given what we know about what may be happening in the brain of the concussed athlete from the studies reported here, and how long it may take for the signs and symptoms of even more severe intracranial injuries such as subdural haematoma to manifest themselves, how can a trainer, coach, or physician know in a casual sideline examination or evaluation within a couple of minutes what the extent of injury to the brain of the athlete might be? He is guessing that everything will go well with the athlete, and that if it does not that something will happen to give him another chance to protect the athlete and to correct his assessment of the seriousness of the injury and his management. Sometimes, unfortunately, the next thing that happens simply aggravates the situation seriously, or even irretrievably.

As a physician attending athletes on the field and in other situations for many years, I made it a practice never to compromise in the management of an athlete with a concussion. Once that injury was identified by me, whether by my own observation alone or with the assistance of a trainer, coach, official or the athlete himself, that athlete did not return to practice or play that day. If he were able to do so he remained close to me, standing, sitting or lying down, where I could converse with him, repeat my observations as often as necessary, and give him reassurance and support. Headache is often not immediate after the injury, arising minutes or even hours later. If there had been more than a brief period of loss of consciousness and there were other neurological symptoms or signs of significance the player went into the dressing room under observation or directly to the hospital.

In more than 30 years of following these policies I never had a complaint from an athlete, trainer, coach or a relative of the athlete. I was fortunate never to see a player die of a head injury, and none who did not recover completely, even from a severe brain injury. I retired one football player permanently from the game after he had suffered three concussions over a 2-year period; one who had apparently suffered an intracranial injury that we did not identify when it occurred because he never showed any sign or symptom of a concussion during a practice or game but complained of a persistent headache for several weeks which led eventually to a finding of old blood in his cerebrospinal fluid; and one who would not keep his head up going into the line and finally suffered a severe forehead laceration after several concussions in one season.

A classification of the severity of concussion that is often seen describes mild, moderate and severe categories. Absence and presence of loss of con- sciousness is supposed to differentiate the first two and an arbitrary time lapse of consciousness the third from the second. Other than this I have never been able to find any other clearly defined and generally accepted group of symptoms or signs that could reliably help tell one degree from another. A concussion is a brain injury, and what might seem to be a mild one at first could appear to be moderate or severe $10 \mathrm{~min}$ later, even if nothing else happens in the meantime. A player who is confused or disoriented, even if only slightly so at the time he is examined, cannot protect himself properly and may be dangerous to others.

When should you allow a player with a concussion to return to practice or play? Certainly not in the same day. Some have said in response to that, 'Soon you would have half the football team sitting on the bench'. Not in my experience; I never had more than two concussions in any one practice or game on the same team. As far as subsequent days are concerned, it depends on a number of things. A single lateral film of the skull should have been made, to check at least for sign of a fracture, and additional films if there was any reason to think them necessary. The presence of a fracture, even if undisplaced, would be a factor in making the decision. The presence of any abnormal neurological sign would be important. Results of neuropsychological testing might be important as well.

One of my most important guidelines was the presence of headache. I would never allow an athlete with a post-traumatic headache to return to a contact sport. In my experience athletes could be relied on to report headache since it is a symptom that scares them. When they reported it gone, and if everything else was all right, I allowed them to return, but cautioned them that if the headache returned during a workout to stop and return to me the next day. In this way they would gradually ease back into practice and games.

I seldom ordered an electroencephalogram. These will usually show some abnormal slow wave activity after a concussion, but this may persist for months and is not helpful. If the computer-automated brain scan had been available when I was taking care of athletes there would have been some times when I would have ordered it. It can be a very valuable tool, even if it is an expensive one.

Finally, in a patient with a concussion, what you can see and find out by other means is certainly important in appraising his/her situation and charting a course. What you do not and can not see may be equally important and sometimes more important. Do not deceive yourself into thinking that you can make these decisions always correctly in a few minutes on the field of play.

\section{Protective headgear}

Although an entire lecture could be devoted to the development of protective devices for the head in sports, a brief discussion regarding what they can or cannot do to protect the brain will suffice. Helmets of different types and qualities have been developed for use by athletes engaged in American football, ice 
hockey, baseball, lacrosse, wrestling, gliding, cycling, parachuting, boxing, equestrian sports and motor sports. With the exception of wrestling and boxing these are hard-shell plastic, usually polycarbonate. Fencers use a mask which covers the head but is designed primarily to protect the face. Although the plastic mouthguard is worn to protect the teeth it may also serve to protect the brain by absorbing some of the impact of a blow to the mandible.

The concept of wearing a helmet in boxing originated with the ancient Greeks and resulted in a device called the amphotides. It was made of leather, studded with iron knobs and was padded internally. We do not know how its originators felt its wearer would be protected. It was used only in gladiatorial contests and never in the Olympic or other games of that period. Fighters in training, both before and after the general introduction of gloves for sparring and prizefighting, often wore a knotted handkerchief around their forehead or padded leather straps over their head. There was not any notion that this would prevent an injury to the brain. The modern boxing helmet was at first padded with horsehair but more recently with rubber or plastic foam. It is required in amateur boxing in the USA but not in Olympic boxing or prizefighting, although professionals use it in sparring and exhibitions.

The helmet currently available has some ability to decelerate blows at the point of impact, as demonstrated by Hodgson ${ }^{13}$. It does nothing to decrease the torque caused by blows to the side of the head or below the the jaw, which turn the head from the midline or upwards and backwards at an angle as the boxer stands or moves forward or backward. Its added weight, although not considerable when it is dry, may actually provide added momentum to the head and increase the torque, as well as the tendency of the leather glove to stick to the helmet momentarily before sliding off. It serves mainly to prevent haematomas of the ears and lacerations of the scalp, forehead and eyebrows. Brain injuries, some of which have resulted fatally, have occurred in boxers wearing both older and modern boxing helmets.

The mechanism of the production of an injury to the brain and its covering is complex because of both the effects of direct impact of the gloved fist on the skull and the relative motion of the brain and skull in response to this impact. These factors have been studied experimentally in both humans and animals by scientists interested in preventing brain injury in automobile and other accidents, as well as in boxing and other sports such as race-driving and ice hockey.

The brain is suspended within the skull by the attachment of its blood vessels and some nerve fibres to its tough elastic covering the dura mater, the outer layer of which is attached in several places to the periosteum of the inner surface of the skull, and by the cerebrospinal fluid which lies between the two inner coverings of the brain, the arachnoid membrane and the pia mater. This suspension allows some movement of the brain within the skull, and because of its relatively great weight it manifests considerable inertia.

Mawdsley and Ferguson ${ }^{14}$ point out that when a gloved fist strikes the head there is a transient acceleration of the head and some deformation of the skull, which is itself a living structure. The latter was demonstrated clearly in the studies of Gurdjian and Webster ${ }^{15}$. This happens whether or not the person struck is wearing a boxing or even a football helmet. The skull moves faster than the brain because of the inertia of the latter, and as the skull comes to rest the brain continues to move in the direction supplied by the impact. As Denny Brown and Russell ${ }^{16}$ explained, the brain impacts on one or several of the bony ridges or prominences of the skull's interior surface and/or the relatively sharp edge of the dural attachment. This causes the contusions or lacerations known as contrecoup injuries because they occur on the side of the brain opposite to the point of impact on the skull. At the same time some of the force of impact is taken up directly by the brain and small haemorrhages (petechiae occur in the cerebral hemispheres and even in the brain stem. These indicate the destruction of nerve cells (neurones) in these areas. These impact forces are said to to be responsible for the syndrome of symptoms and findings that we call concussion. Concussion may cause a momentary decrease in consciousness or may result in a complete loss which is temporary or may be lasting.

If at the time of impact of the fist on the skull from the midline or in the vertical plane there are shearing strains on the brain and its coverings, as described by Holbourn ${ }^{17}$, and swirling movements in the brain, as described by Pudenz and Sheldon ${ }^{18}$, these factors can cause damage in the neurones of the brain and degeneration of nerve fibres, as shown by Strich ${ }^{19}$. Even more important for the immediate effect, the cerebral veins which empty into the sinuses of the dura and which are thin-walled and do not have valves, may be torn, producing the blood pool beneath the dura which we call subdural haemorrhage. If the increased pressure on the brain from this event is not relieved it may cause further damage to brain substance and even death.

A forceful impact may also stimulate the reticular activating centre in the brain which is critical in maintaining erect posture. This stimulates a postural righting reflex, as demonstrated by Govons ${ }^{20}$, which causes a rapid counter-rotation of the head. This causes the concussed individual to throw his body forcefully to the floor of the ring. This knockout punch creates another impact on the head from its contact with the canvas, ring post, ropes, or even through the ropes onto a scorer's table, as occurred with one boxer whose circumstance is reported briefly among those with other catastrophic brain injuries listed later in this report. The boxing helmet is not designed to absorb impacts of that type completely or successfully. The counter-rotation can produce further damage to the brain and its blood vessels.

Over the past 42 years I have accumulated reports of 14 boxers who have suffered catastrophic and fatal brain injuries while boxing or sparring while wearing a boxing helmet. One was a professional boxer who was sparring and two were amateurs, one of whom was sparring with a professional (see Appendix). 
I recently assisted a young man who now manifests significant symptoms and findings of brain damage following a boxing match at his university in 1987 and who is now virtually unemployable, in a suit against the manufacturer of the boxing helmet he was wearing. The suit was settled out-of-court for the absolute limit of the manufacturer's liability insurance. The basis for the action was the implied warranty of the manufacturer that the wearer's brain would be protected.

No boxing helmet can protect the brain from injury when the head is struck with the force of a trained boxer wearing a glove weighing $8 \mathrm{oz}$ when dry and twice as much when soaked with water and sweat as it becomes during a fight. Brain injuries will continue to occur among boxers at all levels concordant with the number of bouts fought over time until the boxing gloves are removed. Facial lacerations and broken noses will occur but these are not chronically disabling and fatal injuries. The ungloved boxer who delivers a punch to the jaw or the side of the head will break bones in his hand and he knows it.

The best hard-shell football helmet will not in all cases protect the brain from the enormous forces directed against it in the collisions of heavy football players. The helmet contains a sticker inserted by the manufacturer which says:

WARNING: No helmet can prevent all head or neck injuries a player might receive while participating in football

A reduction in these injuries has been possible only by making and enforcing stringent rules against using the helmeted head in blocking and tackling. The introduction of the plastic helmet in 1939 and its subsequent modification and improvement encouraged coaches and players to use it as an offensive and defensive weapon.

The ice hockey helmet is effective in preventing injury to the head and the brain from impact of the stick and puck since the mass is relatively small although delivered at relatively high speeds. It unfortunately creates the illusion among players that it will protect in the event of hard checks against the boards. An increase in fractured cervical spines has occurred with some quadriplegias and deaths. Rules against such checking are being tightened and officials must enforce these rules strictly.

Helmets for skiing and equestrian sports can protect the brain more effectively because the principal risk they must accept is a single fall, usually against a stationary object, where little torque is involved. In lacrosse, protection is needed against the stick, and in the USA and Canada the helmet is required for boys and women. The Women's Lacrosse Association has refused to require it because they have said that its use is contrary to the image of women's lacrosse.

The baseball helmet is now required during batting at all levels of play. It has been successful in greatly reducing the number of serious brain injuries and eliminating fatalities almost completely. Since it is not ordinarily worn while playing in the field or after reaching base with a hit, some brain injuries continue to occur as a result of players colliding or being hit by thrown or batted balls.

\section{Heading the ball}

Injuries to the brain occur in soccer because the ball is struck with the head as an offensive and defensive tactic and sometimes players may strike their heads together when both are going for the ball. These injuries are seldom of serious immediate consequence but their long-term effects may be serious. Tysvaer and Storli ${ }^{21}$ of the National Hospital University Clinic in Oslo reported in 1989 on their neurological study and evaluation of 69 football players, aged 15-34 years, from six Norwegian First Division League Clubs. Twenty-seven of the players from this League were not included in this study because of past histories of brain injury not related to football. The neurological examinations and electroencephalogram (EEG) records of these 69 players were compared with 69 age-matched controls none of whom had played football or suffered head injury.

Four of the study group had EEG recordings made before and after heading a soccer ball in an experimental situation and two more recordings immediately after a match. One of them had suffered two concussions during the match. Of the 69,37 (54\%) had in the past suffered head injury during a match and four had reported concussions. Of the 37, eight $(12 \%$ of the 69$)$ reported protracted symptoms of brain injury and two had permanent complaints. Only one had positive neurological findings and these were minimal.

Of 38 players who had acute or protracted complaints, $16 \%$ showed abnormal EEG findings compared with the 31 without complaints, among whom only 3\% showed such findings. The four players in the experimental series experienced headache and showed EEG abnormalities after $10 \mathrm{~min}$ of heading. The player who had two concussions during the match had an EEG showing generalized cerebral dysphasia, and his EEG was still abnormal 2 months later. Among six players with abnormal EEGs, repeat EEG examination 8 years later showed persistent abnormalities in two. Younger players seemed to be more at risk.

The plastic-coated football weighs 397-454 grams (14-16 ounces) when dry and as much as twice that when wet. It is driven at speeds in elite competition from 60 to $120 \mathrm{~km} / \mathrm{h}$ and impact on the head at $10 \mathrm{~m}$ has been measured at $116 \mathrm{kPa}$. A logical question might be, why are helmets not worn? The answer is twofold: the players will say that they could not control the ball with the head encased in a helmet; the referees might say that it would encourage violence in a game that is already dangerous enough. The engineer would tell you that under ordinary conditions of play the helmet would not do much more to prevent brain injury than the boxing helmet does. I can tell you that as long as heading the ball is part of soccer there will be brain injuries of the type and degree just discussed.

\section{Conclusion}

The availability and use today of superior imaging devices makes it possible for physicians to make more 
accurate diagnosis of brain injuries in athletes when they do occur, allowing early and effective treatment which can reduce disability and may prevent fatality.

None of the knowledge based on research and experience, the development and use of protective equipment or the ability to make better recommendations for management of brain injuries based on precise diagnosis will prevent all catastrophic injuries unless coaches, trainers and athletes commit themselves to safe performance skills.

\section{References}

1 Hugenholtz H, Richard MT. Return to athletic competition following concussion. Can Med Assoc J 1982; 127: 827-9.

2 Nevin NC. Neuropathological changes in the white matter following head injury. J Neuropath Exp Neurol 1967; 26: 77-84.

3 Peerless SJ, Rencastle NB. Shear injuries of the brain. Can Med Assoc J 1967; 96: 577-82.

4 Chason JL, Hardy WG, Webster JE, Gurdjian ES. Alterations in cell structure of the brain associated with experimental concussion. J Neurosurg 1958; 15: 135-9.

5 Gurdjian ES, Thomas LM, Hodgson VR, Patrick LM. Impact head injury. GP 1968; 37(2): 76-8.

6 Lindgren SO. Studies in head injuries: intracranial pressure pattern during impact. Lancet 1964; i: 1251-3.

7 Lynch S, Yarnell PR. Retrograde amnesia: delayed forgetting after concussion. Am J Psychology 1973; 86(3): 643-5.

8 Gronwall D, Wrightson P. Delayed recovery of intellectual function after minor head injury. Lancet 1974; ii: 605-9.

9 Gronwahl D, Wrightson P. Cumulative effect of concussion Lancet 1975; ii: 995-6.

10 Taylor AR, Bell TK. Slowing of cerebral circulation after concussional head injury: controlled trial. Lancet 1966; ii: 178-80.

11 Rimel RW, Giordani B, Barth JT, Boll TJ, June JA. Disability caused by minor head injury. Neurosurgery 1981; 9(3): 221-8.

12 Strong I, MacMillan R, Jennett B. Head injuries in accident and emergency departments at Scottish hospitals. Injury 1978; 10: 154-9.

13 Hodgson VR, Thomas LM. Boxing gloves compared using dummy head acceleration response. Department of Neurosurgery, Wayne State University

14 Mawdsley C, Ferguson FR. Neurological disease in boxers. Lancet 1983; ii: 795-801.

15 Gurdjian ES, Webster JE. In trauma of the central nervous system. Mental Advances in Disease 1945; 24: 48.

16 Denny Brown D, Russell WR. Experimental cerebral concussion. Brain 1941; 64: 7-163.

17 Holbourn AHS. Mechanics of head injuries. Lancet 1943; ii: 438.

18 Pudenz RH, Sheldon $\mathrm{CH}$. The lucite calvarium: a method for direct observation of the brain. J Neurosurg 1946; 3: 487-505.

19 Strich SJ. Shearing of nerve fibers as a cause of brain damage due to head injury. Lancet 1961; ii: 443-8.

20 Govons SR. Brain concussion and posture the knockdown blow of the boxing ring. Conferences in Neurol 1968; 30: 77-84.
21 Tysvaer AT, Storli OV. Soccer injuries to the brain: a neurologic and electroencephalographic study of active football players. Am J Sports Med 1989; 17(4): 573-8.

\section{Appendix}

Boxers who sustained catastrophic and fatal brain injuries while wearing a boxing helmet

1. Anthony Scuozzo, 16, Golden Gloves fighter, died after sustaining a subdural haemorrhage, 1947.

2. Charles Mohr, 21, University of Wisconsin, sustained subdural haemorrhage in collegiate match and died following surgery, 1960.

3. William Markley, 18, Portland, Maine, died with brain haemorrhage after sparring injury, 1971.

4. Mike Britton, 16, light flyweight, Wichita Falls, suffered technical knockout on 11 May 1973. Died 23 June 1973 following brain surgery.

5. Richard C. Mull, 19, West Point cadet, following a bout wearing $16 \mathrm{oz}$ gloves, died of brain haemorrhage on 19 May 1977.

6. Ronnie Newton, welterweight, Lake Charles, Louisiana, blood clot removed from brain 15 May 1979.

7. Benjamin Davis, 22, Albuquerque, Golden Gloves fighter, died after brain injury 15 February 1982.

8. Charles Love, 19, US Army boxer, welterweight, was not knocked out in bout on 9 October 1982 but died of injury on 17 October 1982.

9. Jeremiah Richardson, 25, Miami, Florida, was reported to be in a coma on 7 October 1983 following boxing bout.

10. Howard Brookes, 24, Miami, Golden Gloves superheavyweight, collapsed in ring on 25 February 1985 and died 11 March 1985 of brain injury.

11. David Harris, New York, professional light heavyweight, fell unconscious while sparring and died of brain injury on 2 October 1985.

12. Wade Bisher, 18, Billings, Montana, was knocked out and fell through the ring ropes, striking his head on the scorer's table. He died of brain injury on 2 December 1985.

13. Harold Watts, 24, Las Vegas, died 10 July 1988 of brain haemorrhage sustained in sparring with a professional boxer.

14. Bruce Caudillo, 18, Kansas, Golden Gloves fighter, operated on for subdural haemorrhage on 17 January 1989 one week after bout. 